tives are truly to be understood, the search must continue for a theoretically sound, validated instrument.

Sarah Todd: Department of Marketing, University of Otago, PO Box 56 Dunedin, New Zealand. Email〈Stodd@commerce.otago.ac.nz〉.

\title{
REFERENCES
}

\author{
Cossens, J. \\ 1989 Positioning a Tourist Destination: Queenstown-A Branded Destination? \\ Unpublished dissertation, University of Otago, New Zealand. \\ Maslow, A \\ 1943 A Theory of Human Motivation. Psychological Review 50:370-396. \\ Pearce, P., and M. Caltabiano \\ 1983 Inferring Travel Motivation from Travelers' Experiences. Journal of Travel \\ Research 11(2):16-20. \\ Shoemaker, S. \\ 1989 Segmentation of the Senior Pleasure Travel Market. Journal of Travel \\ Research 17(3):14-21.
}

Submitted 10 December 1998. Resubmitted 25 February 1999. Resubmitted 29 March 1999 Accepted 30 March 1999.

PII: S0160-7383(99) 00038-9

Pergamon

www.elsevier.com/locate/atoures
Annals of Tourism Research, Vol. 26, No. 4, pp. 1024-1027, 1999 (C) 1999 Elsevier Science Ltd. All rights reserved Printed in Great Britain $0160-7383 / 99 / \$ 20.00+0.00$

\section{A Model of Tourism Experience and Attitude Change}

\author{
Luis Gomez-Jacinto \\ Jesus San Martin-Garcia \\ Carla Bertiche-Haud'Huyze \\ University of Malaga, Spain
}

There is a common, although questionable, viewpoint that tourism has great potential for improving intercultural relationships. However, research on positive attitude change in tourists visiting a given location (Amir and Ben-Ari 1985; Anastasopoulos 1992; Milman, Reichel and Pizam 1990) questions this claim since contradictory results point to the existence of theoretical gaps. Only in some cases are the results positive. But in the majority of research, attitude change is negative, maybe because attitudes previous to traveling are negative and the format of organized trips does not contribute to contact between tourists and residents. The lack of clearer conclusions might have its source in the non-in- 
clusion of certain other determinant or concomitant factors effecting attitude change. Fisher and Price (1991) developed a model that includes such factors. Their model includes the reasons for traveling as factors for determining the amount of intercultural interaction of tourists with the place visited. This intercultural interaction influences the perceived level of satisfaction with holidays and the positive change of attitudes toward the place visited. The latter is also influenced by the satisfaction level of the tourist. However, the cited work has some limitations, such as, its crosssectional approach and its methodological weaknesses regarding the analysis of causal relations.

The current study follows the Fisher and Price model and is based on their recommendations for future research. A longitudinal investigation was carried out in the area of the Costa del Sol in Spain. Some new variables that complete the model proposed by Fisher and Price were added. For example, to assess tourists' attitudes towards the Spanish, respondents were asked about their stereotype of Spanish people. At the beginning of the holiday they responded to a questionnaire about their beliefs about the Spanish character (such as being passionate, warm, sensual, happy, rude, funny, lazy and hospitable). At the end of their stay they responded to a similar questionnaire after interacting with Spanish people. These new variables are a different and more indirect way to assess their attitude. The other new variables are the amount of tourist activities during their stay including assessing the quality of service and infrastructures. The importance of these additional constructs arise from studies (Ryan 1997) exploring the influence of the nature and characteristics of the destination

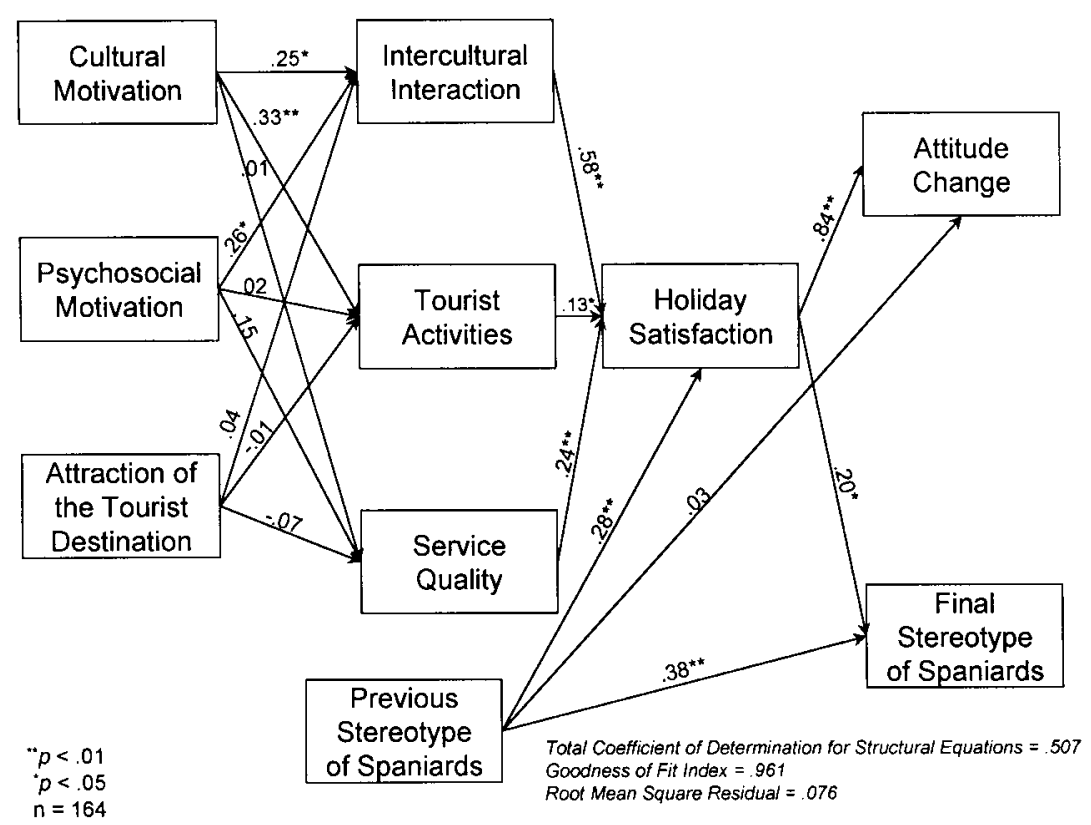

Figure 1. Path Diagram of the Structural Model 
regarding satisfaction and attitude change. These new constructs were used as explanatory variables of the level of satisfaction with their holiday and a change of attitude towards Spaniards (Figure 1). The extended model, for reasons of parsimony, only includes direct influences. Specifically, the model proposes that the influence of intercultural interaction, tourist activities, and service quality on attitude and stereotype is completely indirect, mediated by holiday satisfaction.

In order to test the model, 164 French and Italian tourists were studied. They stayed in Torremolinos for an average of 10 days. The questionnaire was filled in by 73 males and 91 females aged between 16 and 76 (the mean age was 43.5 years). On arriving at the hotel, the tourists were given a questionnaire in which the aim of the research was briefly described. The questions were grouped in two parts: the first was to be filled in immediately and the second on the last day of their stay. Following previous research on tourism motivation (Fakeye and Crompton 1992; McGehee, Loker-Murphy and Uysal 1996) three types were distinguished: cultural, destination attraction (pull), and psychosocial needs (push). In addition, the stereotype tourists held of Spanish people was evaluated. The second part of the survey contained questions divided into six factors: the level of intercultural interaction, the amount of activities engaged in, evaluation of the quality of service and infrastructure, holiday satisfaction, attitude change towards Spaniards, and stereotype of Spaniards at the end of their stay.

The model in Figure 1 was analyzed using LISREL 7 software (Jöreskog and Sörbom 1989) and estimated by Unweighted Least Squares. This figure also shows standardized structural coefficients and global results that indicate a reasonable fit of data to the proposed model. The attraction of the destination has no effects. Cultural motivations increase the quantity of activities engaged in. Psychosocial motivation has only significant effects on intercultural interaction. The original stereotype of the Spanish has a positive influence on holiday satisfaction and on the final stereotype, but not on the change of attitude. Holiday satisfaction is positively influenced by the quantity of activities, intercultural interaction, and the quality of services. Finally, holiday satisfaction strongly increases positive attitude change towards the Spanish. It also improves, although in a less intense way, the final stereotype of the Spanish.

Generally speaking, Fisher and Price's model has been verified with the extensions utilized in this research. Contrary to the traditional motivation ideas at the Costa del Sol, it is the cultural one which best explains the activity displayed by tourists during their visit. Obviously, this activity is linked to some strong interactions with the residents which, in turn, makes them good indicators of post-vacation satisfaction. Psychosocial motivations were thoroughly fulfilled by the interaction with Spaniards and the quality of the services provided. It should be remembered that push factors tend to be good predictors of satisfaction and repeating the trip (Fayeke and Crompton 1992). As in the research cited earlier, the interaction with the host country is a vitally important aspect of tourism experiences. Similarly, pre-vacation attitudes are crucial in the explanation of changes following the holiday (San Martín 1997). It is also significant that there is more influence on positive attitude change toward the Spanish than on improving the stereotype. The indirect nature of this last measure makes the replies less biased by social desirability than in the case of attitude change mentioned by tourists. Therefore this could be a better indicator of attitude change. In addition, it is possibly a more reliable measure of the tourists' true attitude towards Spanish people. The 
use of indirect and non-general measures of attitude are recommended for future research.

Luis Gomez-Jacinto: Departamento de Psicologia Social y de la Personalidad, Facultad de Psicologia, Universidad de Malaga, Campus Universitario de Teatinos s/n, 29071 Malaga, Spain. Email〈jacinto@uma.es〉.

\section{REFERENCES}

Amir, Y., and R. Ben-Ari

1985 International Tourism, Ethnic Contact and Attitude Change. Journal of Social Issues 41:105-115.

Anastasopoulos, P. G.

1992 Tourism and Attitude Change. Greek Tourists Visiting Turkey. Annals of Tourism Research 19:629-642.

Fakeye, P., and J. Crompton

1992 Importance of Socialization to Repeat Visitation. Annals of Tourism Research 19:364-367.

Fisher, R. J., and L. L. Price

1991 International Pleasure Travel Motivation and Post Vacation Cultural Attitude Change. Journal of Leisure Research 23:193-208.

Jöreskog, K. G., and D. Sörbom

1989 Lisrel 7: A Guide to the Program and Applications. Chicago: SPSS.

McGehee, N., L. Loker-Murphy, and M. Uysal

1996 The Australian International Pleasure Travel Market: Motivations from a Gendered Perspective. The Journal of Tourism Studies 7(1):45-57.

Milman, A., A. Reichel, and A. Pizam

1990 The Impact of Tourism on Ethnic Attitudes: The Israeli-Egyptian Case. Journal of Travel Research 29:45-49.

Ryan, C.

1997 The Tourist Experience: A New Introduction. London: Cassell.

San Martín, J.

1997 Psicosociología del Ocio y el Turismo. Málaga: Aljibe.

Submitted 27 August 1998. Resubmitted 28 November 1998. Resubmitted 12 February 1999. Accepted 15 April 1999.

PII: S0160-7383(99)00063-8 